STEPAN G. AKTERIAN

\title{
TOWARDS OPEN ACCESS SCIENTIFIC PUBLISHING
}

\author{
Stepan G. Akterian \\ Department of Technology of Tobacco, Sugar, Vegetable and Essential Oils, \\ University of Food Technologies, Plovdiv, Bulgaria
}

\section{ABSTRACT}

Here my aim is to relate, in outline, the two general models for scientific publishing - subscription-based and open access. Accordingly, the features and the ways for realising of two main types of open access publications - Gold open access and Green open access - are described. The quest to know the basic difference between these two types of open access continues. In addressing them I also highlight their current diffusion and some forecasts for their further extension. The open access publishing is a part of the subsequent goal for open science. Altogether, the present review should hopefully help the reader to appreciate what is required to advance knowledge, and how to benefit from open access publishing. Biomed Rev 2017; 28:125-133

Keywords: publishing model, gold open access, green open access, open science, predatory journals

\section{INTRODUCTION}

Objects of the present review are publications in scholarly and scientific journals. The latter are periodicals carrying accounts of research written by the investigators themselves and published after due peer review as opposed to journalistically based magazines. Journals form a core part of the process of scholarly communication and they are an integral part of scientific research itself. The scientific journals have traditionally four main functions: (i) registration - third-party establishment by date-stamping of the author's precedence and ownership of an idea, (ii) dissemination - communicating the findings to its intended audience usually via the brand identity of the journal, (iii) certification - ensuring quality control through peer review and rewarding of authors, and (iv) archival record - preserving a fixed version of the paper for future reference and citation.

In 2012, 28.1 thousand active scholarly peer-reviewed journals published 1.9 million articles. The number of journals and the number of articles published grow at a rate of 3 $\%$ and $3.5 \%$ per year. The global output of research papers is distributed as follows: $21 \%$ USA, $10 \%$ China, $7 \%$ UK, $6 \%$
Japan, $6 \%$ Germany, $4 \%$ France, and $46 \%$ for the rest of the world. The summarized output of European countries is 23 $\%$. The science and engineering journal articles produced in EU were 250 thousand in 2009. However, the citations of US authors are $30 \%$ of the total amount of citations. Researchers read average 270 articles per year and spend about 30 minutes per article. The peer reviewing remains the fundamental of scholarly communication. The typical reviewer referees eight articles spending five hours per a manuscript (1).

\section{TRADITIONAL MODEL FOR SCIENTIFIC PUBLISHING}

Until the beginning of the current millennium, the scientific publishers only operated a subscription-based model or tollaccess model, whereby they charged universities money for subscriptions. In some cases, universities can be charged up to USD 25,000 for a single journal annual subscription. The publishers controlled what research would be impactful and significant enough to warrant publication. Taken together, a large institution could therefore pay millions a year for all of the journals in its library (2). However, this is a difficult achievement for a limited number of universities and institu-

Received 16 November 2017, revised 2 December 2017, accepted 3 December 2017.

Correspondence and reprint request to Dr Stepan G. Akterian, Department of Technology of Tobacco, Sugar, Vegetable and Essential Oils, University of Food Technologies, Plovdiv, Bulgaria. E-mail: akterian@abv.bg 
tions even in Europe.

The annual revenues generated from English language scientific, technical and medical journal publishing (STM) were estimated at about USD 9.4 billion in 2011. About $52 \%$ of global STM revenues come from the USA, $32 \%$ from Europe and Middle East, $12 \%$ from Asia and Pacific region and $4 \%$ from the rest of the world (1).

Researchers submitting papers to traditional academic publishers do not get payment, even when they hand over their copyright. This means that the traditional publishers get their articles, their peer reviewing (vetting by other researchers) and even much of their editing for free. The scientific findings they publish are the results of research funded not by these publishers, but by taxpayers through government research grants. However, according to this model, the free public access to the publications is denied (2). Everyone must pay to the publisher about EUR 40 for the privilege having a limited license to read a single article, if he/she is not affiliated with rich universities.

\section{OPEN ACCESS PUBLISHING MODEL AND ITS DEVELOPMENT}

The term "open access" (OA) was introduced in 2002 when the Open Society Institute released the "Budapest Open Access Initiative" (3). Open access to peer-reviewed journal literature was their final goal. They recommended two main strategies for achieving open access to scholarly journal literature: (i) self-archiving - the authors deposit their refereed journal manuscripts in open electronic archives, and (ii) open-access journals - the authors' articles are disseminated free and widely without a charge for subscription or fees for access.

The authors do not give the copyrights to the publisher. The publishing expenses are covered by the authors, the universities and laboratories that employ researchers, the foundations and governments that fund research or by special public funds.

Open access publication was defied in "Bethesda Statement on Open Access Publishing" in 2003 (4). It should meet the following two conditions. First, the authors and copyright holders grant to all users a free, irrevocable, worldwide, perpetual right of access to, and a license to copy, use, distribute, transmit and display the work publicly and to make and distribute derivative works, in any digital medium for any responsible purpose, subject to proper attribution of authorship. Second, a complete version of the work and all supplemental materials, including a copy of the permission as stated above, in a suitable standard electronic format is deposited immediately upon initial publication in at least one online repository that is supported by an academic institution, scholarly society, government agency, or other well-established organization that seeks to enable open access, unrestricted distribution, interoperability, and long-term archiving.

This statement expresses the desire of scientists to maximize benefits of the scientific community and the public from scientific knowledge. The participants of the working group recognize that publishing is a fundamental part of the research process, and the costs of publishing are a fundamental cost of doing research.

"Berlin Declaration on Open Access to Knowledge in the Sciences and Humanities" (5) from 2003 supported Bethesda's definition of Open Access Publication. The scientists of this group outlined the scope of Open access contributions: original scientific research results, raw data and metadata, source materials, digital representations of pictorial and graphical materials and scholarly multimedia material. They encouraged the researchers to publish their work according to the principles of the open access paradigm. They initiated developing means and ways to evaluate open access contributions and online-journals in order to maintain the standards of quality assurance and good scientific practice.

In 2012 the European commission in its Recommendation 2012/417/EU (6) prescribes all member states to disseminate in open access form the scientific results from publicly funded research. The publications should be open access as soon as possible, preferably immediately and in any case no later than 6 months after the date of publication, respectively - 12 months for social sciences and humanities. The academic career system should support and reward researchers whose publications are open access. The public research funds and academic institutions receiving public funding should ensure open access to scientific publications. This document of EC also recommends dissemination and open access to research data resulting from publicly funded research. These data should become publicly accessible, usable and reusable through digital e-infrastructures. An effective system of deposit should ensure e-preservation and reuse of scientific information. The general requirement of Horizon 2020 - EU Framework Programme for Research and Innovation in the period 2014 to 2020 - is that all results should be published as Open access - Gold or Green OA.

Three European national Academies (Academie des sciences, Leopoldina and Royal Society) released "Statement on scientific publications" (7) in 2016. They listed the follow- 
ing principles of Good science publishing: (i) efficient and high-quality dissemination of scientific information, (ii) the avoidance of all forms of conflict of interest, (iii) the necessity to ensure fair reviewing of articles, and (iv) keeping the handling and decision-making processes regarding scientific articles entirely under the control of well recognised scientists. They plead for "objective peer review, which emphasizes scientific quality, methodological rigour and statistical soundness over potential impact, novelty and fashionability". The academicians add that the principle of anonymity of the reviewers must be respected unless they have chosen to waive it. They support both "green" and "gold" routes to open access and believe that the funds currently spent on journal subscriptions should be redirected to fund publication charges. They express their position that the payment of an article processing charge must be clearly separated from the editorial decision. To minimise delays in the dissemination of research findings, articles should also be deposited in open archives and preprint repositories. The academicians propose that each publication in these systems should not be a hindrance to later publication in a scientific journal.

On 27 May 2017, the competitiveness Council of EU ministers of science, innovation, trade and industry published a progressive commitment calling for full open access to scientific research by 2020 . They had the ambition the results of research supported by public and public-private funds to be made freely available to public. They discussed different ways for realisation of OA goal: Green OA by deposing scientific outputs in institutional repositories or Gold OA, supported by the Dutch government, according to which authors should publish in OA journals. However, the council of competitiveness did not express a preference for either route. The council calls for "immediate" OA, "without embargoes" or with as short as possible embargoes. A spokesperson of the council said "This is not a law, but it's a political orientation for the 28 governments. The important thing is that there is a consensus." (2).

\section{VARIETIES OF OPEN ACCESS PUBLICATIONS}

The biggest publisher Elsevier (8) and other publishers offer two main types of OA publishing: gold and green.

1. Gold open access. The final published version of an article is made accessible immediate and permanent via the publisher's website to anyone, free of charge, as soon as it is published. This kind of publications is offered by the following three types of scholarly journals:
1.1. Fee-based open access journals. They publish all their articles as OA. They do not have any subscribers, and instead everyone can read all the content online for free. Elsevier publishes over 120 peer-reviewed, OA journals, including Cell Reports and Lancet Global Health. The authors or funding body on their behalf have to pay an OA publication fee or article processing charge (APC). The latter is in the range from USD 500 to USD 5,000 USD for Elsevier journals (8) and USD 3,000 for Springer journals. The article processing charge for publishing in the mega-journal PLOS (Public Library of Science) was USD 1,495 in 2015.

The Directory of Open Access Journals (https://doaj.org) includes information for 11,208 OA journals from 123 countries and 2,923,263 articles. 8,145 journals are searchable at article level. One third of the DOAJ-indexed OA journals have JCR impact factors. The number of OA medical journals is 648 or their share is $5.8 \%$. The number of medical articles listed in this directory is 11,208 and their share is 7.4 $\%$. However, this directory does not include all open access journals.

The market of reputable OA journals was estimated at 244 million USD for 2013 out of a total STM journals market of USD 10.5 billion (9). This means that OA journals market is approximately $2.3 \%$ of the total STM journals market.

1.2. Hybrid journals. These journals are subscription journal, but they publish OA articles as well. After acceptance the authors can choose how to publish the article. Elsevier proposes an OA option in over 1,600 established subscription journals that support open access publishing (8).

1.3. Subsidized journals. They are both free to read and free to publish in for everyone. These journals are fully supported by government, affiliated organizations or a society who provide funds to cover all the costs of publication, including the OA for all authors. The journal Biomedical Reviews (what you read now) can be also subsumed in this group of OA journals.

2. Green open access. The author deposits a self-archiving version of his/her article in an OA non-commercial repository where it is online accessible free of charge to readers. The version may be either the manuscript submitted to the journal, or the post-peer-review version accepted by the journal. The author can post his/her accepted manuscript immediately to an institutional repository and make it publicly available after an embargo period has expired. The embargo is a period of time set by the publisher in the copyright transfer agreement with the authors. Typical embargo periods vary from 6 to 24 months, though some publishers may require an embargo of 
up to 48 months. The embargo periods of Elsevier journals are in the range from 6 to 36 months. The embargo period is 12 months for scientific, technical, medical, and psychology journals of Wiley publisher and 24 months for social science and humanities journals of this publisher.

3. Pseudoacademic open access journals or predatory publishing. The term "predatory journal" or "predatory publisher" was coined in 2010 by American librarian Jeffrey Beall (10) to describe unscrupulous OA publishers who were publishing articles with little or no real peer review. These publishers exploit OA publishing business model that involves charging publication fees to authors without providing the editorial and publishing services associated with legitimate scholarly journals. Beall's list (https://beallslist.weebly.com) of potential, possible or probable predatory scholarly OA publishers includes 1,124 publishers. In this list there are very well sounding names as Academic and Scientific Publishing, American Scientific Publishers, Austrian Scientific Publication House, BioMed Press, British Association of Academic Research, Canadian Science and Technology Press Inc., Columbia International Publishing, European Union Research Publishing, Frontiers in Bioscience, Global Publishing Corporation, Impact Journals (USA), International Academic Publishing House, Noble Academic Publisher, Open Access Publishing Group, Scholarly Research Publisher, Spring International S\&T Publishing Media Co, PubMedHouse. Beall published criteria (10) for determining Predatory OA publishers. His criteria can be grouped as follows:

- Editorials as: the journal does not identify a formal editorial board; no single individual is identified as the editor of journal; the journals have an insufficient number of board members (e.g., 2 or 3 members); there is little or no geographical diversity among the editorial board members, especially for journals that claim to be international in scope; no academic information (e.g., institutional affiliation) is provided regarding the editor and editorial board members.

- Publishing management as: the publisher does not use standard identifiers such as ISSN or DOI or uses them improperly; the publisher lists insufficient contact information as headquarter location, post address, phone numbers; there is insufficient information about author fees; publishing of papers that are not academic by nature, e.g. polemical editorials or obvious pseudo-science articles; re-publishing of papers that are already published in other venues/ outlets; provide minimal or no copyediting or proofreading of submissions; the publisher produces journals that are excessively broad (e.g., Journal of Education) or which combine two or more fields not normally treated together (e.g., International Journal of Business, Humanities and Technology); the publisher charges authors for publishing, but requires transfer of copyright and retains copyright on journal content; the publisher has poorly maintained websites, including dead links, grammatical errors, etc.; the publisher engages in excessive use of spam email to solicit manuscripts or editorial board memberships; none of the members of the editorial board has ever published an article in the journal.

Shen and Björk (11) evaluated that around 1,000 predatory publishers maintain around 8,000 active journals. The latter brought out 420,000 articles in 2014. The average number of articles per year in these journals is around 50 and it is comparable to the figures in DOAJ-indexed OA journals. The largest share of articles were classified as "general" (38.5\%), engineering (23\%) and biomedical (17\%). The biggest part $(27 \%)$ of predatory publishers is located in India, following in the North America (17.5\%). The location of $27 \%$ of these publishers was impossible to be determined. Forty two percent of single-journal publishers were from India. Sixty percent of corresponding authors were from Asia (and $35 \%$ of them were from India), $16.4 \%$ were from Africa (and $8 \%$ were from Nigeria) and $9.2 \%$ from North America. The average duration for publishing in predatory journals is 3 months. The average delay for the legitimate scholarly OA journals is 6 months. The publishing delay in subscription-based journals is much longer as it varies from 9 to 18 months. The article processing charge (APC) for articles in predatory journals in the period 2010-2014 varied from USD 83 for singlejournal publishers to nearly USD 800 for big publishers with 100 and more journals. Shen and Björk (11) evaluated that the market of predatory journals was USD 74 million for 2014. That means that the market of predatory OA journals was 23 $\%$ of the total market of OA journals. Solomon and Björk (12) revealed that only $10 \%$ of the APCs for OA publishing came from personal funds in the case of authors from countries with a GDP per capita of over USD 25,000. However, 39 $\%$ of the authors from developing countries (with a GDP per capita under USD 25,000) paid from their own pockets for OA publishing. For that reason, generally the authors from low-income countries turn to low-cost predatory journals with an average APC of USD 178. The production of predatory publication in 2014 was compared with the high quality articles according to the Web of Science from the same country. The ratio of predatory articles to Web of Science-indexed ones for the USA, Iran, India and Nigeria - the four biggest 
contributors of predatory articles - were respectively $6 \%, 70 \%, 277 \%$ and $1,580 \%$ (11).

Similar findings were also reported for specialized medical journals. Manca et al (13) listed 87 predatory journals in the neurosciences and 101 in neurology. A large part of these journals pointed that their headquarters are in the USA (35.3-42.0\%) and India (19.0-39.2\%). Manca et al (14) identified 59 predatory journals in the field of rehabilitation. Most of them were based in India (36\%) followed by the United States $(25 \%)$ and Pakistan (5\%). Tosti and Maddy (15) specified that the predatory journals in the field of dermatology are 76 journals or $89.5 \%$.

Many scientists (13-18) expressed their concerns and apprehensions for the negatives at the blooming of predatory OA journals in the field of medical journals as the reliability of results and conclusions, the integrity of reporting research, preserving the integrity of the forensic medical database. This medical information published is critical because the rules of clinical practice are based mainly on the findings reported in scholarly articles.

On the other hand, it is very difficult to draw a dividing line between the predatory journals of Beall's "grey" list and the "white" journals indexed by Journal Citation Reports of Thomson Reuters, Scopus, Web-of-Science and DOAJ.org. Some "white" journals, even ones indexed by JCR, employ some practices pointed as unacceptable in Bell's criteria (10). Examples of such practices are "The publisher asks the corresponding author for suggested reviewers", "The publisher requires the copyright transfer upon submission of manuscript", "No single individual is identified as any specific journal's editor". I am familiar with many OA journals, which provide quality, adequate editorial and publishing service, with APCs up to USD 100, but still not indexed by JCR. I cannot label these journals as "predatory" provided that there are "white" OA journals with an APC of USD 3,000 or even USD 5,000.

\section{CURRENT STATUS OF OPEN ACCESS PUBLISHING}

The development of OA publications and traditional subscription-based publications are compared in Figure 1. In 2018 the amount of OA articles will overtake subscription-based ones.

The forecast of the Web of Science for the deal of OA

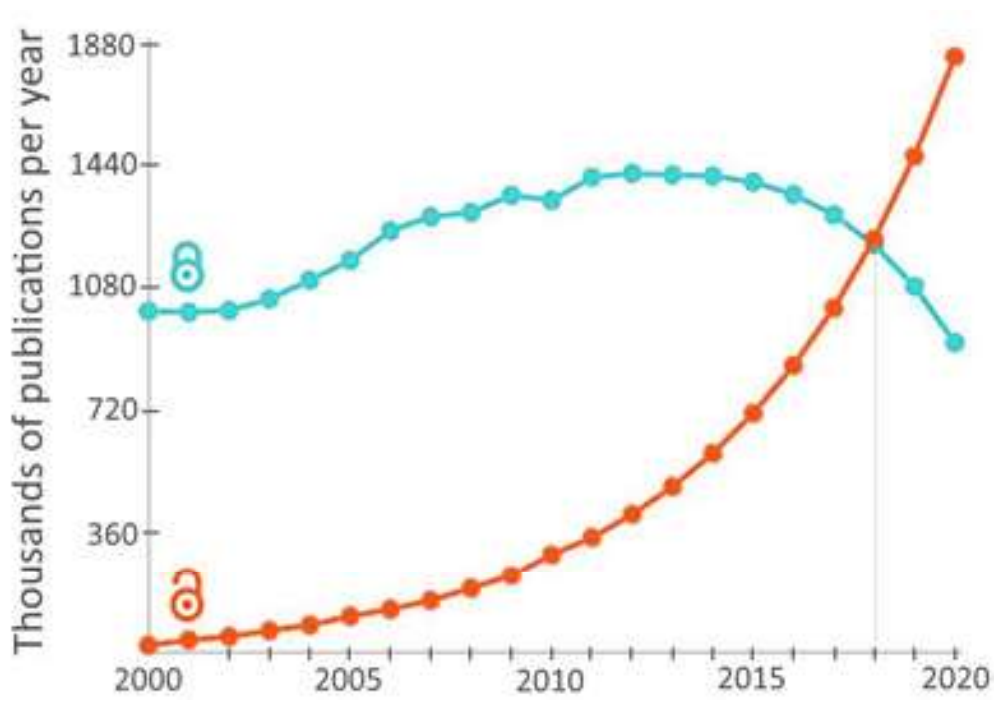

Figure. 1. Comparison of the development of Open access publications (marked with an open padlock) and Subscription-based publications. From (2) with adaptation.

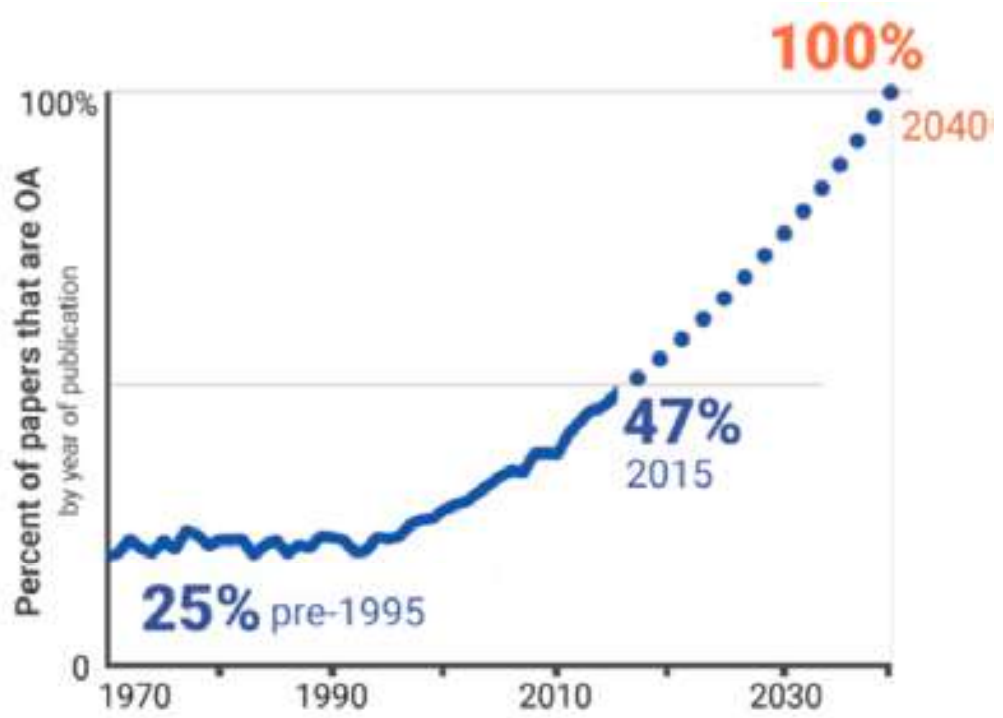

Figure. 2 Forecast of the share of Open Access publications according to the Web of Science. From (19) with adaptation.

publication is presented in Figure 2 and it is more optimistic. According to the diagram $50 \%$ of publications are already OA in 2017. It is expected that $100 \%$ of scientific publications will be Open Accessed in 2040.

The distribution of Gold and Green OA publications for different scientific areas is presented in Figure 3. The biggest share of Gold OA publications are in the area of (bio) medicine, genetics and cell and molecular biology. The dy- 


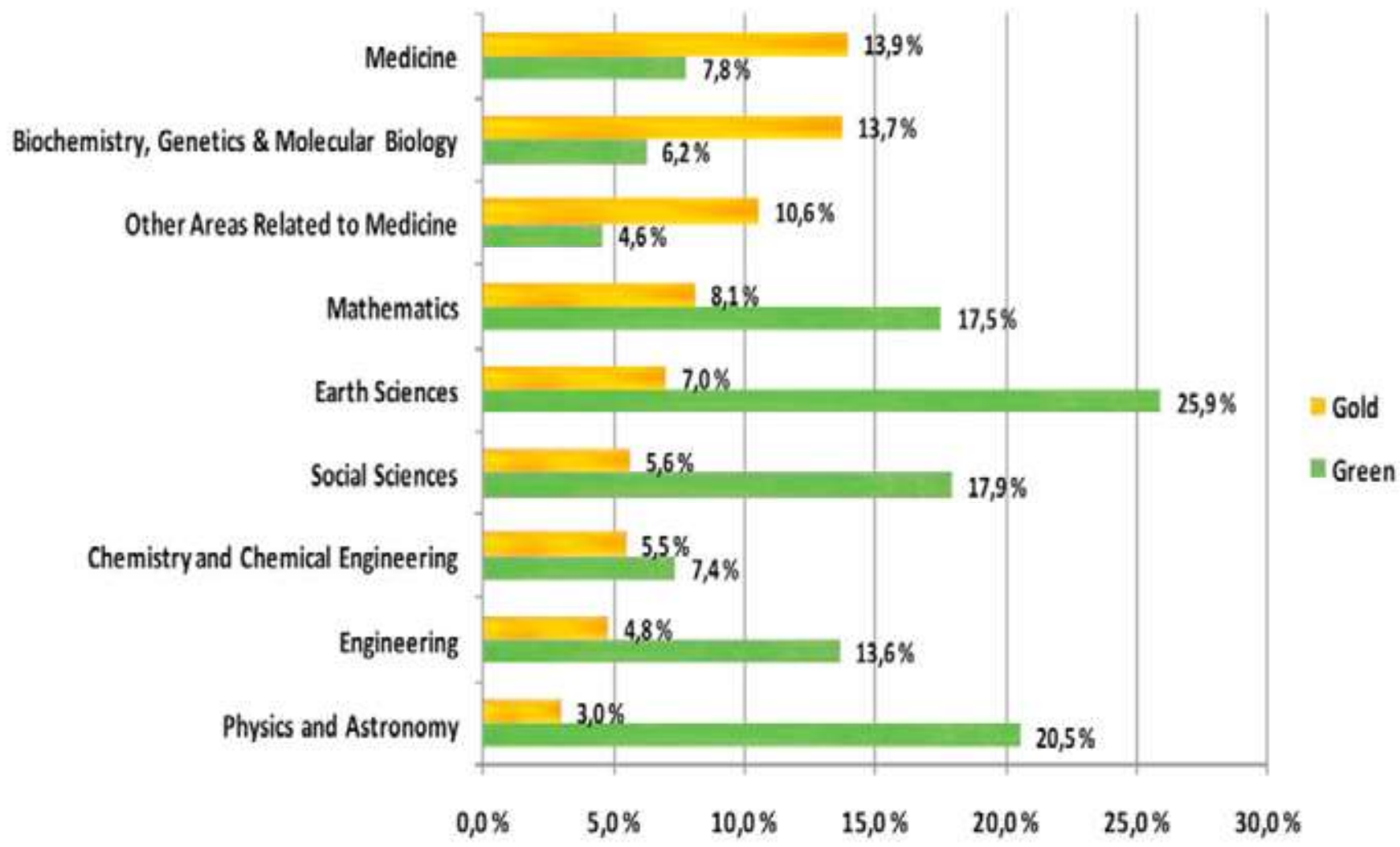

Figure. 3 The share of Gold and Green Open access publications for different scientific areas in 2009. From (20)

namics of new knowledge in these areas is the highest (for instance, see Denys Wheatley's Eureka review in this volume of Biomedical Reviews). This requires any new information to be immediately accessible in full-text. The lowest level (12.9 $\%$ ) of OA publications is in the area of chemistry and chemical engineering. I suppose that this is due to technical and business advantages of new knowledge revealed. The highest share (over $20 \%$ ) of Green OA publications are in the area of earth sciences, physics and astronomy. In this case, the knowledge published cannot be easily commercialized. On the other hand, the period of a single study is longer.

\section{TOWARDS OPEN ACCESS SCIENCE}

Open science is the idea that scientific knowledge of all kinds should be openly shared as early as is practical in the discovery process (by Michael Nielsen, http://michaelnielsen.org/ blog/open-science-2).

Open science is based on the following six principles (http://openscienceasap.org/open-science) for opening substeps and results of the scientific process: (i) open methodology, (ii) open sources (open-source technology - software and hardware - and open proprietary technologies), (iii) open data, (iv) open access to the results, (v) open peer review: transparent and traceable quality assurance through open peer review, and (vi) open educational resources using free and open materials for education and in university teaching. The first four principles were introduced in (21).

The model of Open science according to the EU research project FOSTER (Facilitate Open Science Training for European Research, https://www.fosteropenscience.eu) is presented in Figure 4. This model was adopted by the Directorate-general for research \& innovation of EC and it is presented in its Website.

The model shows that OA to scientific publications is a central spot in the architecture of new Open Science paradigm. A new specific feature in this architecture is Open peer reviewing. The latter is in a contrast of traditional blind peer reviewing. The other general characteristics of Open science are Open research data and Open scholarly communication.

The first Open database called Genomic Data Commons http://portal.gdc.cancer.gov was launched in 2016. It was a project of the National Cancer Institute (USA) and it was cre- 


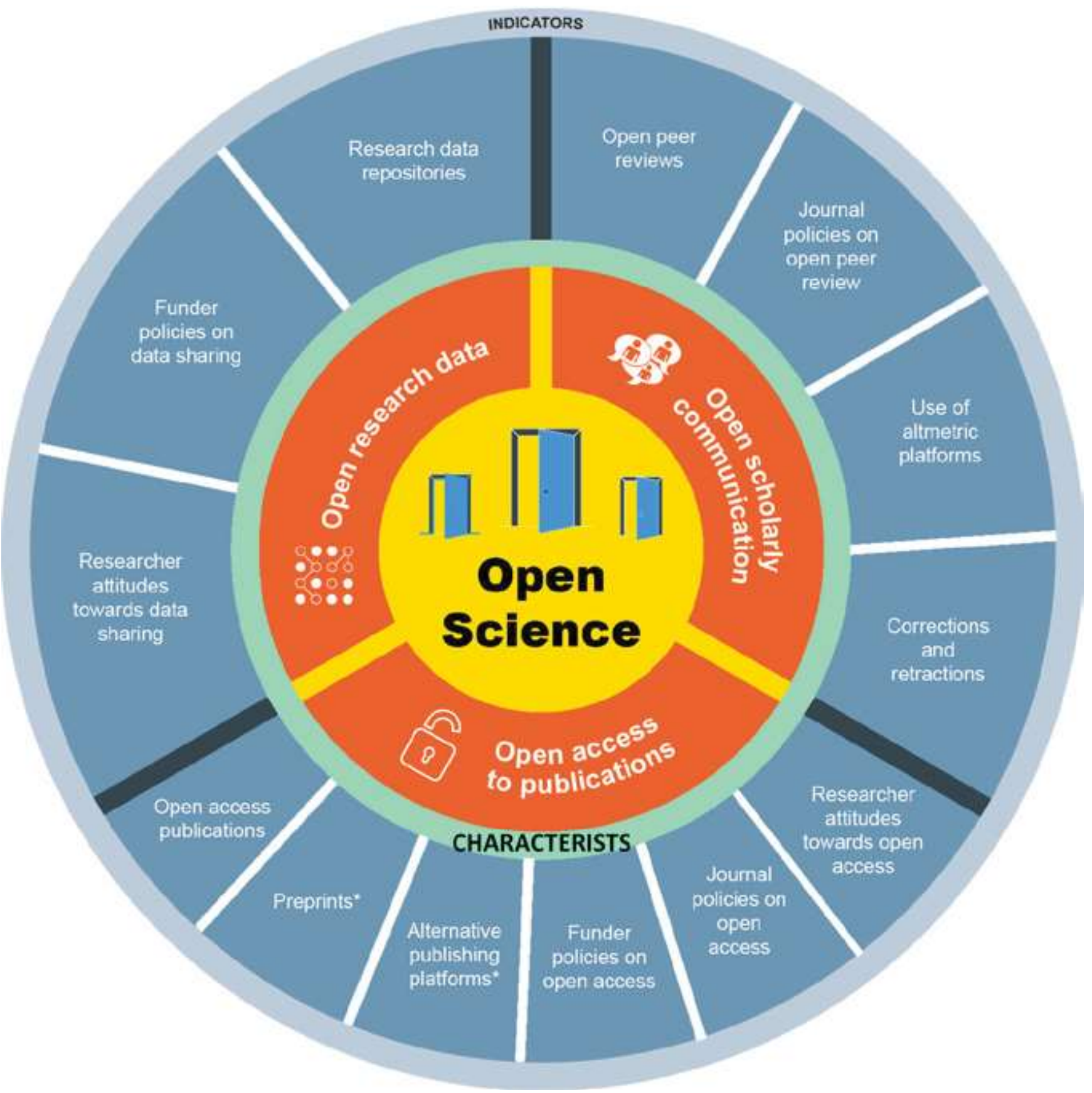

Figure 4. Model of Open science according to the European commission. The sectors coloured in pomegranate and Boston blue are related to the characteristics and indicators, respectively. From (22) with adaptation.

ated by the University of Chicago, Center for Data Intensive Science and the Ontario Institute for Cancer Research. This database includes two petabytes of genomic information for $3,115,606$ mutations in 22,144 genes and clinical data for 12,000 patients. The database could be used by physicians, researchers, and life science companies to better understand the diseases, to develop more effective treatments and to help a cure for cancer.

FINAL REMARKS, concerning the EU initiative for full Open access from 2020

The idea for OA scientific literature and Open science resources is a dream of every scientist. For that the goal of establishing full OA in EU by 2020 should be admired. The 
Gold OA alternative is very promising for the big publishers and their lobbies. Indeed, the Gold OA is a brilliant business model for publishers. So, they could collect revenues before their product is released on the public market.

However, the Gold OA alternative frightens the regular Bulgarian scientist and not only. According to the recent requirements the scientific reputation of Bulgarian university is evaluated on the base of publications in journals indexed in Scopus and the Web of Science. Therefore, the carrier development of scientists will be also determined from their publication in above-pointed journals. For the most of these journals the article processing charges (APC) vary from USD 500 to USD 5,000 USD. These APCs can be only funded in the framework of European projects and in some cases from the National Fund for Scientific Investigations. However, the access to these funds is very limited in practice. The university budgets and local funds for scientific studies are very limited. Most Bulgarian authors should pay for the publication of their manuscripts in foreign journals by themselves, indeed. The financial situation is especially hard for Bulgarian PhD students whose monthly scholarship is around EUR 250 and the annual budget for research is around EUR 400. Unfortunately, Bulgarian Ministry of Education and Science is also in an uneasy situation. An indicator of this is the impossibility to provide financially the national access to Science direct and Scopes databases. Not surprisingly therefore, since 1990 the Bulgarian brain drain has been taking a huge dimension for our country. That is, many postgraduates - well prepared and devoted to make research work have been moving to Western universities, where they realizing their talent publishing in journals indexed in Elsevier, Scopus, PubMed and Web of Science.

\section{CONFLICT OF INTEREST STATEMENT}

The author certifies that he has no affiliations with or involvement in any organization with any financial interest in the subject matter discussed in this review article.

\section{REFERENCES}

1. Ware M, Mabe M. The STM Report. An Overview of Scientific and Scholarly Journal Publishing. The Hague, International Association of Scientific, Technical and Medical Publishers. 2012.

2. Hall N. If science is going to save the world, we need to make it open. 2016, accessed on 3.11.17.

3. Open Society Institute. Budapest Open Access Initiative.
Budapest. 2002, accessed on 3.11.17.

4. Scientists and Scientific Societies Working Group. Bethesda Statement on Open Access Publishing. Bethesda (USA). 2003; http://legacy.earlham.edu/ peters/fos/ bethesda.htm, accessed on 3.11.17.

5. Berlin Declaration on Open Access to Knowledge in the Sciences and Humanities. Berlin. 2003; https:// openaccess.mpg.de/Berlin-Declaration, accessed on 3.11.17.

6. Commission recommendation of 17 July 2012 on access to and preservation of scientific information (2012/417/ EU). Official J Eur Union, 20 July 2012; 55(L192):39-43.

7. Academie des sciences, Leopoldina and Royal Society. Statement on scientific publications by three national Academies. 2016; https://www.leopoldina.org/en/press/ press-releases/ press-release/press/2451/, accessed on 12.11.17.

8. Elsevier Publisher. Your Guide to Publishing Open Access with Elsevier. Oxford, 2015; https://www.elsevier.com/about/open-science/open-access , accessed on 3.11.17.

9. Esposito P. The size of the open access market. The Scholarly Kitchen. 2014; http://scholarlykitchen.sspnet. org/2014/10/29/the-size-of-the-open-accessmarket. accessed on 20.11.17.

10. Beall J. Criteria for determining predatory open-access publishers. 2015, accessed on 19.11.17.

11. Shen C, Björk B. 'Predatory' open access: a longitudinal study of article volumes and market characteristics. BMC Medicine 2015; 13(230):1-15. DOI 10.1186/s12916-0150469-2.

12. Solomon D, Björk B-C. Publication fees in open access publishing: sources of funding and factors influencing choice of journal. JASIST 2012; 63:98-107. DOI:10.1002/ asi.21660.

13. Manca A, Martinez G, Cugusi L, Dragone D, Dvir Z, Deriu F. The surge of predatory open-access in neurosciences and neurology. Neuroscience 2017; 353:166173.

14. Manca A, Martinez G, Cugusi L, Dragone D, Mercuro G, Deriu F. Predatory open access in rehabilitation. Arch Phys Med Rehabil 2017; 98(5):1051-1056.

15. Tosti A, Maddy AJ. Ranking predatory journals in dermatology: distinguishing the bad from the ugly. Int $J$ Dermatol 2017; 56(7):718-720.

16. Hua F, Shen C, Walsh T, Glenny AM, Worthington H. Open access: Concepts findings, and recommendations 
for stakeholders in dentistry. J Dentistry 2017; 64:13-22.

17. Johal J, Ward R, Gielecki J, Walocha J, Natsis K, Tubbs RS, et al. Beware of the predatory science journal: A potential threat to the integrity of medical research. Clin Anat 2017; 30(6):767-773.

18. Knoll JL. Open access journals and forensic publishing. $J$ Am Acad Psychiatry Law 2014; 42(3):315-321.

19. Clarivate Analytics. Whitepaper Web of Science: Opening the way to Open Access. Philadelphia, 2017; http://info. clarivate.com/openaccess, accessed on 3.11.17.
20. Björk B, Welling P, Laakso M, et al. Open access to the scientific journal literature: Situation 2009. PLoS ONE 2010; 5(6): e11273. DOI:10.1371/journal.pone.0011273

21. Kraker P, Leony D, Reinhardt W, Reinhardt W. The case for an open science in technology enhanced learning. Int J Technol Enhan Learn 2011; 3(6): 643-654.

22. Directorate-general for research and innovation of European Commission. Open Science Monitor. https://ec.europa.eu/research/openscience/index.cfm?pg=home\&section=monitor accessed on 12.11.17. 